\title{
LO FANTÁSTICO Y EL HIPERREALISMO EN "LA REBELIÓN DE LOS NIÑOS” DE CRISTINA PERI ROSSI
}

\author{
Fantasy and hyperrealism in "La rebelión de los niños" by Cristina Peri Rossi
}

Mariela Mata Li*

\begin{abstract}
RESUMEN
El siguiente artículo plantea una interpretación del cuento de Cristina Peri Rossi "La rebelión de los niños" desde el género fantástico. Para argumentar este planteamiento, el hiperrealismo, como subgénero literario, resulta un mecanismo que permite la creación de un contexto realista, el cual, por su parte, provee el contraste necesario para enfatizar la transgresión, característica primordial de un suceso fantástico. "La rebelión de los niños" describe un futuro distópico regido por una dictadura opresiva, en la cual las generaciones más jóvenes, llenas de un intelecto macabro y coraje, deciden vengar a sus padres desaparecidos y construir un nuevo futuro.
\end{abstract}

Palabras clave: Literatura fantástica, Hiperrealismo, Literatura acerca de niños, Literatura distópica, Cuentos latinoamericanos.

\begin{abstract}
The following essay proposes an interpretation of Cristina Peri Rossi's short story "La rebelión de los niños" based on the fantastic genre. To support this thesis, hyperrealism as a literary subgender is the mechanism that allows the creation of a realistic context, the one which in turn provides the contrast necessary to emphasize the transgression that characterizes a fantastic event. "La rebelión de los niños" describes a dystopian future ruled by an oppressive dictatorship, in which the younger generations, full of an macabre intellect and courage, decide to avenge their parents disappearance and build a new future. Key Words: Fantastic literature, Hyperrealism, Literature about children, Dystopian Literature, Latin American short stories.
\end{abstract}

Universidad de Costa Rica. Costa Rica.

Correo electrónico: marielamta@gmail.com

Recepción: 08/8/14. Aceptación: 18/5/15. 


\section{Lo fantástico como género literario}

A diferencia de la opinión popular que con frecuencia asocia al género fantástico con lo irracional, lo ilógico o lo onírico, es decir, con el polo opuesto de la literatura realista; la crítica literaria considera lo contrario, pues el realismo no sólo se integra naturalmente dentro de la literatura fantástica, sino que se convierte en una "necesidad estructural de todo texto fantástico" (Roas, 2001:24). La explicación de lo anterior se remonta a la misma definición de lo fantástico, en donde críticos, tales como Tzevetan Todorov o David Roas, afirman que debe existir una transgresión o ruptura de aquello que era considerado como real, borrando las barreras de lo imposible y creando inestabilidad en un mundo que pretende ser completamente racional.

De esta forma, lo fantástico se manifiesta en el instante en que se produce el contraste entre la realidad y el fenómeno sobrenatural, siendo necesario que el texto represente el mundo más "auténtico" posible, para que así, comparativamente, se produzca un mayor efecto fantástico. Asimismo, la literatura fantástica está complementada por dos géneros "vecinos": lo extraño y lo maravilloso, los cuales también se definen por el rol (o la falta de uno) que tiene la transgresión dentro de ellos. Se trata de un relato de lo extraño si la ruptura es explicada de manera racional, atribuyendo los hechos sobrenaturales al azar, la ilusión de los sentidos o la locura, mientras que, si no hay ruptura, es decir, lo sobrenatural es tomado como algo "normal" y cotidiano que no provoca reacción alguna ni los personajes ni en el lector, se trata de un relato enmarcado en lo maravilloso.

Lo fantástico viene a constituirse como un género basando en la contradicción, pues, aunque su existencia se encuentra permanentemente inscrita en la realidad, al poner en duda nuestra percepción de la realidad, el género también se convierte en "un atentado contra esa misma realidad que lo circunscribe" (Roas, 2001: 25). Debido a lo anterior, el crítico David Roas prefiere plantear a lo fantástico como una especie de "hiperrealismo", que, además de reproducir las técnicas de los textos realistas, obliga al lector a constantemente confrontar sus experiencias de la realidad con aquellas de los personajes en el texto.

\section{Hiperrealismo como escenario para lo fantástico}

Precisamente, es esta característica hiperrealista la que se puede atribuir al cuento "La rebelión de los niños" (1980) de la uruguaya Cristina Peri Rossi. Situado a finales de los años sesenta, el cuento, sin entrar en detalles, hace alusión a un país del cono sur que, después de un levantamiento armado durante 1965, ha caído en un régimen dictatorial. Debido al temor de una nueva subversión, los hijos pequeños de quienes participaron en la rebelión contra el gobierno fueron despojados de sus padres, separados de sus hermanos y reacomodados con familias adoptivas o en reformatorios:

\footnotetext{
Para evitar que ambos pudiéramos complotarnos contra la seguridad de Estado y organizar la subversión, nos habían separado: a mí, me había tocado pasar a vivir con una de las más rancias familias del país, de probada fidelidad a las instituciones, desde hacía más de cincuenta años, tan rígida como dispuesta a borrar de mí toda simiente del pasado; en tanto Pico, menos rebelde, más pequeño, fue a parar a un reformatorio (Peri Rossi, 1992:122).
}

El cuento, escrito en primera persona, presenta un narrador llamado Rolando, quien, a pesar de sus escasos catorce años, posee la auto-percepción, sensibilidad e intelecto de una persona de mucho mayor edad; sin embargo, este rasgo no es exclusivo del narrador, ya que, a medida que avanza el relato, aparece en los demás personajes infantiles, específicamente, en Pico, hermano menor de Rolando, y en Laura, joven que conoce durante el concurso de arte que sirve como trasfondo del cuento. Rolando es un adolescente que, después de ser separado de su hermano Pico, fue adoptado por una familia adinerada y reconocida históricamente como fiel al partido que instauró este régimen dictatorial. Él y los demás hijos de rebeldes fueron dados en adopción para así convertirlos, desde su crianza, 
en ciudadanos "correctos" al servicio de este nuevo Estado.

Entre los esfuerzos de este Estado para terminar de consolidar su poder y desviar las fuerzas subversivas que yacen potencialmente en estos niños, se encuentran varias estrategias: primeramente, se fomenta la pornografía y el fanatismo hacia el deporte, debido a que ambas actividades tienen como fin el provocar la obsesión en los niños y esto, en palabras del mismo narrador, "debilitaría cualquier otra idea peligrosa que pudiera ocurrírsenos" (Peri Rossi, 1992:125). Según Noam Chomsky, lo anterior se clasifica como una forma de manipulación colectiva que implica el distraer a las personas, en este caso a los menores, de la actual situación social, ocupando sus energías e intelectos en temas sin importancia real, es decir, se busca "...mantener al público ocupado, ocupado, ocupado, sin ningún tiempo para pensar; de vuelta a granja como los otros animales" (Chomsky, 2010:2).

Asimismo, otra de las estrategias utilizadas consiste en borrar cualquier registro del pasado; esto con el propósito de impedir la conservación y la reconstrucción de la memoria histórica para estas nuevas generaciones, las cuales son representadas por los niños. Si la memoria histórica preserva y da un valor simbólico a las acciones colectivas vividas durante el pasado de un pueblo, entonces esta se convierte en un peligro para el Estado, pues “...recordar que un día fuimos libres amenaza romper el dominio de quien hoy se aprovecha de nuestras cadenas" (Emmerich, 2011:1). En el cuento, esta invisibilización del pasado se da mediante la prohibición de archivar la información, pues los tutores de estos niños "confían en el rápido deterioro de la memoria" $y$, debido a esto, les impiden cifrar y certificar sus recuerdos documentalmente" (Peri Rossi, 1992:112).

De esta forma, el Rolando hace un recuento de las peripecias que pasó para revisar los ejemplares de los dos últimos años de la Biblioteca Nacional, revisión que tuvo por objetivo encontrar una serie de fotografías (las cuales formaban parte de noticias destacadas), que servirían para tapizar la silla que expondría como su proyecto para el concurso de arte:

\begin{abstract}
Después de seleccionar cuidadosamente el material que me interesaba, recorté varias hojas, llenas de fotografías, y ese fue el papel que usé para tapizar una parte de la silla (...) Un pedazo de papel, por ejemplo, traía la fotografía de un bebé quemado por el napalm en Vietnam (...) También elegí una vista de una manifestación en Córdoba, en el momento de ser disuelta por la policía (...) En otro lugar se veía, enorme, la fotografía de Charles Bronson, con el bigote caído, la pose un tanto felina, el aire de virilidad reconcentrada y muscular que encanta a las mujeres (Peri, Rossi, 1992:114).
\end{abstract}

\section{Peri Rossi y Orwell: Paralelismos distópicos}

El papel del poder estatal en la invisibilización de la memoria histórica, "La rebelión de los niños" establece un paralelismo con la novela 1984 de George Orwell, la cual se enmarca en un género "vecino" de la literatura fantástica: la ciencia ficción. En esta narración, Orwell describe una sociedad distópica con un protagonista que, al igual que Rolando, también cuestiona el sistema y está consciente de la forma en que, literalmente, se borra la historia y se rescriben los sucesos, enajenando a la población:

En cuanto se reunían y ordenaban todas la
correcciones que había sido necesario introducir
en un número determinado del Times, ese número
volvía a ser impreso, el ejemplar primitivo se
destruía y el ejemplar corregido ocupaba su
puesto en el archivo. Este proceso de continua
alteración no se aplicaba sólo a los periódicos,
también a los libros, revistas, folletos, carteles,
programas, películas, bandas sonoras, dibujos
animados, fotografías ..., es decir, a toda clase de
documentación o literatura que pudiera tener algún
significado político o ideológico. Diariamente, y
casi minuto a minuto, el pasado era actualizado
(Orwell, 2008:48).

La misma preocupación que presenta Winston, protagonista de 1984, la padece Rolando, quien teme que, a pesar de sus mejores esfuerzos en dejar "pistas y señales" sin que sus padres adoptivos se den cuenta, el paso del 
tiempo inevitablemente borre de su mente todos los recuerdos que ha intentado conservar:

Leyendo los diarios viejos me di cuenta de la cantidad impresionante de cosas que me había olvidado, durante los días de estos dos años. Cosas tan importantes que pensé no olvidar jamás. Y se trataba solamente de los dos últimos años. ¿Cómo imaginar la cantidad exorbitante de cosas que había podido olvidar desde nacido? (Peri Rossi, 1992:113).

\section{La parodia en función de lo fantástico}

En lo que respecta a la irrupción de lo sobrenatural, característica de todo texto fantástico, "La rebelión de los niños" presenta, en primer lugar, una sociedad que si bien es cierto mantiene la estructura básica de cualquier sociedad, la cual incluye la división socialtécnica del trabajo, los mecanismos de coerción y coacción, y las "reglas del orden establecido por la dominación de clase. (Althusser, 1988: 3); también incluye elementos paródicos que, según Víctor Bravo, "ponen en escena la dualidad del mundo" (1988:47), al no corresponder a una sociedad "realista" propiamente, sino que se está creando una literatura con consciencia de sí misma como ficción.

Entre los elementos fantástico-paródicos que posee esta sociedad, se encuentra la promoción del sexo y la pornografía entre los niños y adolescentes:

De modo que nuestros padres adoptivos, nuestros maestros y profesores, se ocupan tenazmente de fomentar en nosotros los intereses sexuales, por lo cual nunca nos falta material ameno e ilustrativo para entretener nuestros ocios (Peri Rossi, 1992:125).

El rasgo anterior resulta inverosímil al tomar en cuenta la forma en que, históricamente, la sexualidad ha sido un tema tabuado. Prueba de ello, han sido épocas tan profundamente conservadoras como el periodo victoriano, en donde "se cubrió alrededor del sexo un manto de silencio: nadie hablaba de nada relacionado con él, ni siquiera de nada que hiciese una mera alusión a él" (Salomón, s.f), o en los años ochenta con la epidemia del sida, especialmente dentro de la comunidad homosexual de Nueva York, en donde esta enfermedad, en ese momento prácticamente desconocida, provocó terror, a tal punto que, un simple beso en la mejilla se convirtió en una amenaza. Debido a ejemplos como los anteriores, la promoción del sexo y aún más cuando se da entre menores, resulta un planteamiento fantástico del relato en comparación con la realidad.

\section{Una niñez sin inocencia}

Continuando con los rasgos sobrenaturales en "La rebelión de los niños", el relato presenta como segundo elemento fantástico a personajes infantiles que, a pesar de su corta edad, poseen un intelecto y una sensibilidad superiores a las de cualquier adulto, de manera que no se limitan a respetar las convenciones sociales que les han sido impuestas. Lo anterior es ejemplificado, primeramente, por el mismo Rolando, quien menciona, desde sus variados intereses académicos:

En realidad me interesaba tanto la plática como la música como la sociología como la medicina como la física como la química, la botánica y la matemática superior (Peri Rossi, 1992:116).

Hasta su inclinación por cometer un acto vedado, tal como lo es el incesto:

Si hubiera tenido una hermana me habría enamorado de ella perdidamente y habría vivido un drama occidental y cristiano, porque los incestos me despiertan admiración, ternura, respeto, sensualidad y placer (Peri Rossi, 1992:120).

Asimismo, Pico, hermano menor de Rolando, es descrito por el mismo como un "adulto", pues, aunque sólo es un niño de siete años, se comporta de forma serena, austera y reservada, con una vida prácticamente monacal, apartándose de lo lúdico para dedicarse solamente a la poesía y a la política.

Según Eric Rabkin (1999), tradicionalmente, el niño ha sido identificado primordialmente por su condición de haber nacido, prueba de ello es que, en idiomas como 
el inglés, la palabra "child" proviene del gótico "kilthei”, que significa "útero". De esta forma, se reconoce como niño a lo opuesto de un ser humano desarrollado, tanto física como mentalmente, de forma completa. El niño es un ser identificable por su susceptibilidad a la muerte y por personificar la inocencia.

Sin embargo, en "La rebelión de los niños" estas expectativas sobre lo que es la niñez son trastocadas, mostrando personajes infantiles que, aunque no han terminado su desarrollo físico, presentan el intelecto de un adulto erudito y eso es lo que los vuelve un elemento perturbador y amenazante. Se trata de niños que, al tener consciencia de su condición y de su entorno, pierden su carácter vulnerable y son difíciles de manipular y controlar. Debido a esto, el Estado toma medidas precautorias como la anteriormente mencionada adopción, la censura de una mayoría de los libros ("Libros, estaban casi todos censurados por una u otra razón y todos los días partían buques repletos para arrojarlos en alta mar" (Peri Rossi, 1992:126)) y la prohibición de manipular objetos cortantes:

\begin{abstract}
Ya se me ha indicado que, para evitar que maneje hojas de afeitar, deberé cortarme estos pelos incipientes en la barba que han empezado a crecer con la máquina eléctrica, porque el uso de la barba está prohibido, nos vuelve sospechosos, pero tampoco podemos manipular objetos cortantes (Peri Rossi, 1992:124).
\end{abstract}

La niñez como un periodo de inocencia ha sido un constructo social, presente desde el romanticismo del siglo XIX, cuando los niños dejan de ser percibidos como "adultos en miniatura" para otorgárseles una identidad separada; en palabras del filósofo francés Jean Jacques Rousseau: "La infancia tiene sus propias maneras de ver, pensar y sentir; nada hay más insensato que pretender sustituirlas por las nuestras" (Rousseau, s.f: 47).

A diferencia de la forma de pensamiento imperante previa al siglo XIX, la modernidad y la posmodernidad (siendo esta última en donde se sitúa la narración) imponen una visión de mundo en la que la niñez es vista como un periodo con una falta de contexto, es decir, ésta presenta la ausencia de un marco en donde ubicar las cosas terribles e incomprensibles que le suceden tanto a la mente como al cuerpo. Rabkin menciona que la emoción clave de la niñez es el miedo, un miedo con el que el niño tiene que aprender a convivir, mientras supera el proceso de relacionarse con el mundo exterior.

Debido a esto, y utilizando la propuesta acerca de lo fantástico de Rosie Jackson, en "La rebelión de los niños" lo infantil pierde su inocencia y su capacidad para inspirar ternura, convirtiéndose en un Otro amenazante. $\mathrm{Si}$ la tradición racionalista, iniciada con $\mathrm{La}$ república de Platón, plantea la expulsión de todas las energías trasgresoras para lograr el funcionamiento del Estado, el cuento de Peri Rossi representa esta ausencia con la desaparición de los padres de los niños ( "Estarán separados, muy lejos, cada uno en su cubil, en lugares remotos, distanciados por kilómetros de caminos de tierra, cercas, alambradas, postes, púas y sirenas, detrás de enormes muros cuyo final no se divisa" (Peri Rossi, 1992:130).)

No obstante, no es posible aplicar la misma estrategia con niños (ya sea porque este Estado no quiera mostrarse tan explícitamente cruel o para no perder ese gran parte de la población) y, debido a esto, se recurre a su reacomodo mediante los reformatorios o la adopción. A pesar de estas medidas, al Estado se le presenta el problema de que estos niños no han podido ser "reprogramados" o moldeados a su preferencia; todo lo contrario, ellos no caen en sus "trampas" y comenten infracciones que van desde despreciar incentivos como la pornografía o el deporte, comunicarse con sus amigos o hermanos que están en el reformatorio, hasta llegar a una venganza final: el quemar vivos a los respetables miembros del Partido Oficial que llegaron a la premiación del concurso de arte.

De esta forma, lo fantástico, encarnado en los personajes infantiles, se convierte en una otredad que representa una resistencia en contra de "la razón homogeneizadora, reductora y unificadora", la cual se asocia con el Amo, figura representativa del orden capitalista y patriarcal, dominante en la sociedad occidental. Así como lo fantástico llama la atención sobre la 
naturaleza relativa de las categorías que pretenden ordenar la realidad humana, logrando ridiculizar y parodiar "toda fe ciega en la coherencia psicológica y en el valor de la sublimación como actividad civilizadora" (Jackson, 2001: 147); en "La rebelión de los niños", el grupo infantil, específicamente Rolando y Laura, critica y se rebela contra el orden impuesto por los aparatos represivos e ideológicos de este Estado.

\section{Transgresión personificada por lo femenino}

Otro aspecto que cobra particular relevancia resulta como, para esta última transgresión, sea una joven, Laura, la principal ejecutante de la venganza, utilizando lo que en un principio se consideraba un inofensivo juego de agua como herramienta para rociar con gasolina a los espectadores de la premiación. Por su parte, Rolando, siguiendo sus instrucciones, se encarga de lanzar una tea ardiente dentro del recinto, matando a todos lo que se encontraban allí dentro.

Se trata de una mujer adolescente que, después de haber ganado el primer lugar del concurso, se encarga, en nombre de los demás niños y jóvenes, de vengar a un régimen patriarcal y tradicionalista, instituido por el “...máximo general de la nación, el héroe de 1965, quien había aplastado la sublevación" (Peri Rossi, 1992:135). Para los niños, se trata de una acción que finalmente brindará justicia a los horrores del Régimen, el cual, debido a su barbarie y en comparación de las mentes sublimes de los niños, ve sus miembros descritos como "antropoides erectos", "primates" y "monos del mundo".

Laura, considerada como la reivindicadora y la depositaria del futuro, utiliza su plataforma como ganadora para llevar a cabo sus planes, en los cuales también hay un homenaje a la sublevación de 1965 y a los rebeldes que fueron víctimas del Régimen, pues cuando en la premiación ella pone a funcionar nuevamente su invención, un juego basado en chorros de agua, los surtidores bañaron con sus trompas a la multitud. No obstante, en esta ocasión ella cambió el agua por gasolina, lo que permitió que el fuego de la tea Rolando se propagara, creando así una imagen semejante a la que ocurrió en las manifestaciones de 1965, en donde "los chorros de agua lanzados por los camiones militares derrumbaban a la gente por el suelo, la hacían girar sobre sí mismos, reptar por las veredas, enceguecidos por el líquido, empujados por el agua" (Peri Rossi, 1992:136).

En conclusión, "La rebelión de los niños" es un cuento que, recurriendo a la técnica del hiperrealismo, representa un estado represivo, en el que los hijos de los rebeldes han sido separados de sus padres y reacomodados en reformatorios o con nuevas familias, todo esto con el fin de reeducarlos para que crezcan siendo miembros correctos y obedientes de esta nueva sociedad. Sin embargo, lo sobrenatural irrumpe personificado en estos niños, quienes, a diferencia de la concepción romántica que se tiene sobre la niñez, no son crédulos, inocentes o vulnerables; por el contrario, son individuos que, estando al tanto de todos los mecanismos que utiliza el Estado para "domesticarlos", utilizan su astucia para rebelarse contra éste. Como golpe de gracia, Laura, ayudada por Rolando, prende fuego al recinto del concurso de arte, quemando vivos a todos los prestigiosos asistentes. De esta forma, el fuego se utiliza como un elemento que purifica, erradicando todo rastro de lo antiguo, y permitiendo el renacer de esta sociedad, guiada por estas nuevas generaciones.

\section{Bibliografía}

Althusser, L. 1988. Ideología y aparatos ideológicos del Estado. Freud y Lacan. Buenos Aires: Editorial Nueva Visión.

Bravo, V. 1988. La irrupción y el límite: Hacia una reflexión sobre la narrativa fantástica y la naturaleza de la ficción. México: UNAM.

Chomsky, N. 2010. 10 estrategias de manipulación mediática. www.archive. 
attac.org/attacinfoes/attacinfo569.pdf. Consulta: 14 de noviembre, 2013.

Emmerich, N. 2011. La memoria histórica: derrota, resistencia y reconstrucción del pasado. Centro Argentino de Estudios Internacionales. ht t p://www.researchgate.net/ publication/220006572_La_memoria_ histrica_derrota_resistencia_y_ reconstruccin_del_pasado. Consulta: $1 \overline{4}$ de noviembre, 2013.

Jackson, R. 2001. "Lo "oculto" de la cultura" en Teorías de lo fantástico: Introducción, compilación de textos y bibliografía. Madrid: Arco/Libros.

Metz, S. s.f. Romantic politics: Romanticism and the Child: Inventing Innocence. University of Tennessee. http://web. utk.edu/ gerard/romanticpolitics/ childhood.html. Consulta: 14 de noviembre, 2013.

Orwell, G. 2008. 1984. Madrid: Ediciones Mestas.
Rabkin, E. 1999. Nursery Realms: Children in the Worlds of Science Fiction, Fantasy, and Horror. Georgia: University of Georgia Press.

Roas, D. 2011. Tras los límites de lo real: Una definición de lo fantástico. Madrid: Editorial Páginas de Espuma.

Peri Rossi, C. 1982. La rebelión de los niños. Barcelona: Editorial Seix Barral.

Rousseau, J. 2000. Emilio o la educación.http:// www.escritoriodocentes.educ.ar/datos/ recursos/libros/emilio.pdf. Consulta: 14 de noviembre, 2013.

Salomón, P. s.f. Freud y Foucault: distintas lecturas acerca de la influencia de la moral victoriana sobre la sexualidad burguesa de fines del siglo XIX. http:// www.elseminario.com.ar/biblioteca/ Salomon_Freud_Foucault.htm. Consulta: 14 de noviembre, 2013

Todorov, T. 2006. Introducción a la literatura fantástica. Buenos Aires: Editorial Paidós.

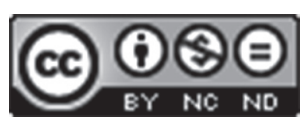

Este obra está bajo una licencia de Creative Commons

Reconocimiento-NoComercial-SinObraDerivada 4.0 Internacional. 
